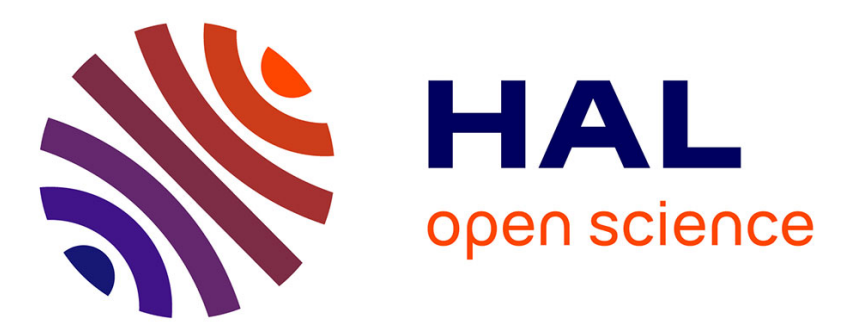

\title{
Oleogelation of rapeseed oil with cellulose fibers as an innovative strategy for palm oil substitution in chocolate spreads
}

\author{
Annabelle David, Mélissa David, Pauline Lesniarek, Emmanuel Corfias, \\ Yoann Pululu, Mathieu Delample, Patrick Snabre
}

\section{To cite this version:}

Annabelle David, Mélissa David, Pauline Lesniarek, Emmanuel Corfias, Yoann Pululu, et al.. Oleogelation of rapeseed oil with cellulose fibers as an innovative strategy for palm oil substitution in chocolate spreads. Journal of Food Engineering, 2020, 10.1016/j.jfoodeng.2020.110315 . hal-02959182

\section{HAL Id: hal-02959182 \\ https://hal.science/hal-02959182}

Submitted on 6 Oct 2020

HAL is a multi-disciplinary open access archive for the deposit and dissemination of scientific research documents, whether they are published or not. The documents may come from teaching and research institutions in France or abroad, or from public or private research centers.
L'archive ouverte pluridisciplinaire HAL, est destinée au dépôt et à la diffusion de documents scientifiques de niveau recherche, publiés ou non, émanant des établissements d'enseignement et de recherche français ou étrangers, des laboratoires publics ou privés. 


\section{Oleogelation of rapeseed oil with cellulose fibers as an innovative strategy for palm oil substitution in chocolate spreads}

Annabelle DAVID ${ }^{\mathrm{a}}$, Mélissa DAVID ${ }^{\mathrm{a}}$, Pauline LESNIAREK ${ }^{\mathrm{a}}$, Emmanuel CORFIAS $^{\mathrm{a}}$, Yoann PULULU $^{\mathrm{a}}$, Mathieu DELAMPLE ${ }^{\mathrm{a}^{*}}$, and Patrick SNABRE ${ }^{\mathrm{b}}$

${ }^{\mathrm{a}}$ : CRT AGIR, 37, avenue Albert Schweitzer, B.P. 100, 33402 Talence Cedex.

b : Univ. Bordeaux, CRPP, UPR 8641, F-33600 Pessac, France

\section{Corresponding author:}

Mathieu DELAMPLE,

Permanent address: CRT AGIR, 37, avenue Albert Schweitzer, B.P. 100, 33402 Talence Cedex.

Tel: 33 (0)5 579683 33; email: m.delample@agir-crt.com

Article type: Research Paper

Declarations of interest: None

Keywords: Oleogels; Vegetal cellulose fibers; Rapeseed oil; Yield stress; Stability; Palm oil substitution. 
2 The texturing properties of mercerized cellulose dispersed in rapeseed oil without any prior

3 thermal treatment were investigated as a function of botanical origin, cellulose content, mass

4 fraction and fiber size through a molecular analysis of samples, macroscopic/microscopic

5 observations and rheological experiments (continuous or oscillatory shear flow). A solid-like

6 behavior of dispersions was demonstrated for a minimum cellulose content of about $60 \mathrm{wt} . \%$ in

7 the vegetal powder. The oleogelation efficiency increases with the mass fraction of powder in oil

8 and the maximum size of cellulose fibers as a result of weak attractive interactions and fiber

9 entanglement giving rise to a network entrapping the liquid phase. An innovative strategy using a

1030 wt.\% dispersion of bamboo fibers in rapeseed oil was finally used to produce in a conch a

11 chocolate spread with a high thermal stability at $38{ }^{\circ} \mathrm{C}$ and healthier nutritional qualities

12 compared to an equivalent product prepared with palm oil. 


\section{Introduction}

Edible oleogels consist in a vegetable oil phase physically entrapped in a continuous macroscopic network at the origin of a semi-solid like rheological behavior. Oleogelation has been the subject of numerous studies in recent years due to the potential substitution of saturated fats (Martins et al., 2018; Patel et al., 2016, 2020; Patel, 2018; Pehlivanoglu et al., 2017; Singh et al., 2017). Indeed, edible vegetable oils with a high content in monounsaturated or polyunsaturated fatty acids are more and more popular with consumers and food manufacturers due to the healthy nutritional qualities of such products. Environmental concerns are another reason to reduce the consumption of saturated fatty acids with the controversial sustainability of some botanical origins such as palm (Khatun et al., 2017).

Fat based products are nevertheless commonly used in food or cosmetic. Fatty acids in a crystallized form ( $\alpha, \beta$, or $\beta$ polymorphs) may self-assemble and then trap the liquid oil phase. However, the formation of a crystallized network requires a high solid fat content to avoid a phase separation (Manzocco et al., 2014) and the melting of fat crystals further reduces both the thermal stability and the shelf-life of fatty acids based products.

Structuring a liquid oil can be achieved by several methods, mainly indirect ones (e.g., emulsification process followed by a complete dehydration) or direct ones through the dispersion of various compounds in the liquid oil phase. Over the last decade, numerous review articles summarize edible constituents and strategies that can be used focusing both on the different types of oleogels and the oleogelation mechanism (Ferreira Chaves et al., 2018; Davidovich-Pinhas et al., 2015; Hwang, 2020; Martins et al, 2018, 2020; Patel et al., 2016; Patel, 2018; Pehlivanoglu et al., 2017). 
Oleogelators can be roughly divided into two categories mainly depending on the molecular weight of molecules. Small molecules (with a molecular weight usually less than about $3000 \mathrm{Da}$ ) are used as structuring agents to entrap the oil phase through the formation of a 3-dimensionnal network. For this purpose, lipid derivatives like fatty acids, lecithins, or mono and diacylglycerol are commonly used. These molecules can self-assemble in the liquid oil phase to form supramolecular structures such as tubular vesicles, micelles or inverse lamellar phases.

Larger molecules and polymers can also be used such as proteins (Mezzenga, 2011; Scholten, 2019) and cellulose derivatives: carboxymethyl cellulose (CMC), ethyl cellulose (EC) or hydroxyl methyl propyl cellulose (HPMC) (Singh et al., 2017; Jiang et al., 2018). The texturing mechanism then consists in the formation of a fibrillar network. According to Martins et al (2018), "the only known polymer that can be used through the direct method to structure oils and approved for food applications is ethylcellulose (EC)". However, the solubilization of EC polymers in oil first requires heating above the EC glassy transition temperature $\left(\approx 140^{\circ} \mathrm{C}\right)$ and then a second stage of cooling induces a conformation transition that promotes inter-polymer hydrogen bonds and the formation of an infinite network entrapping the liquid phase (Martins et al., 2018).

The molecules described above are considered in Europe as food additives and have to be mentioned as an E-number. Consequently, looking for a natural compound as an oleogelator represents a great challenge in the food industry.

Some authors further describe the use of natural seeds or fibers such as cotton, milkweed, wool, kapok or citrus. An oil sorption mechanism was highlighted in relation either with the morphology of fibers in the form of ribbons, ropes or hollow tubes or with a waxy polymer 
surface (Choi \& Moreau, 1993; Likon et al., 2013; Singh et al., 2013; Thilagavathi et al., 2018; Wahi et al., 2013; Zhu et al., 2017).

To the best of our knowledge, no use of vegetal fibers as oleogelators was considered in the literature without prior emulsification or thermal treatment. In such a context, the ability of cellulose fibers to texture an edible oil at ambient temperature without any thermal treatment represents an innovative challenge. The present work concerns the oleogelation of rapeseed oil with mercerized cellulose of different botanical origin. The texturing potential of vegetal powders dispersed in rapeseed oil and the stability of dispersions are first discussed in relation with the molecular composition of powders obtained from a van Soest method. Both light microscopy observations of diluted samples and a rheological investigation of concentrated dispersions in rapeseed oil (flow and oscillatory shear experiments) are further presented to study the impact of cellulose fiber size and powder mass fraction upon the texturing of rapeseed oil. The oleogelation mechanism of cellulose fibers in oil is finally discussed on the basis of light microscopic observations of the interfacial front between the oil phase and the concentrated dispersion. As an industrial application, a solid-like dispersion of bamboo fibers in rapeseed oil is used to make a chocolate spread. The thermal stability and the flow properties of the homemade chocolate spread are investigated as a function of the mass fraction of bamboo powder in rapeseed oil and compared with the characteristics of a homemade chocolate spread prepared with palm oil only.

\section{Materials and methods}

\subsection{Characterization of vegetal powders}

Mercerized cellulose powders were purchased from different providers. Botanical source, purity, and molecular composition are summarized in Table 1. Purity and molecular composition 
of samples display marked differences depending on the botanical origin and the physicochemical treatments realized by manufacturers. The mercerization process consists in an ionic treatment of the native cellulose fibers (cellulose I) in an alkali solution usually followed by a bleaching process with hydrogen peroxide and/or a Kraft mechanical peeling to reduce both the hemicelluloses and the lignins content (non-cellulosic constituents) to get "mercerized" or "regenerated" cellulose (cellulose II) in a more stable form (Kleppe, 1970; Hon, 1994; Li et al, 2018). Other elements such as proteins and starch not mentioned in Table 1 may be dominant in some mercerized powders.

The molecular composition was assessed by Capinov laboratory (France) using the van Soest normalized method (NF V18-122, AFNOR, 2018) which involves successive uses of detergents: (i) a neutral detergent to separate the fiber content in soluble and insoluble fractions; (ii) an acid detergent to quantify the hydrophilic hemicelluloses content; (iii) a sulfuric acid solution to separate and analyze the cellulose and lignins contents.

Table 1 further gives the sieving size of powders provided in the technical documentation but such a granulometric information is only indicative and very dependent upon both particle agglomeration and air humidity. For this reason, light microscopy observations of 0.1 wt.\% diluted dispersions of vegetal powders in rapeseed oil (Metro Chef, France) were performed with a Nikon Eclipse E600 POL microscope. Microscopic pictures show the presence of both polydisperse fibers with a fairly uniform diameter in the range from $10 \mu \mathrm{m}$ up to $20 \mu \mathrm{m}$ and nonfibrous globular particles with a relative proportion depending upon the botanical origin and the cellulose content (Fig. 1). A careful examination of pictures gives the maximum size $L_{\max }$ of fibers and the maximum diameter $D_{\max }$ of non-fibrous globular particles Table 2). 


\subsection{Preparation of dispersions in rapeseed oil and chocolate spreads}

104 Dispersions with a mass fraction of vegetal powder in the range from $5 \mathrm{wt} . \%$ to $40 \mathrm{wt} . \%$ were

105

106

107

108

109

110

111

112

113

114

115

116

117

prepared in rapeseed oil under manual stirring during two minutes at the ambient temperature $20{ }^{\circ} \mathrm{C}$. In the case of a high cellulose content in the powder, the dispersion displays a solid-like behavior for a mass fraction $c_{y i e l d}$ of powder in rapeseed oil ( $\mathrm{c}_{\text {yield }}$ is expressed in wt.\%). The addition of extra powder soon results in a highly viscous dispersion and manual stirring becomes more difficult. When the cellulose content is low, the dispersions remain fluid all along the powder addition and particles settle in a few minutes when stopping the manual stirring. All experiments were conducted in triplicate for each of the samples.

A homemade chocolate spread was prepared either with palm oil or a dispersion of bamboo $\mathrm{Ba} 30$ in rapeseed oil with a mass fraction of powder in the range from $0 \mathrm{wt} . \%$ to $30 \mathrm{wt} . \%$. The different chocolate spreads consist of 50.1 wt.\% of sugar (Tereos; France), 21 wt.\% of palm oil (Alva Food; France) or 21 wt.\% of a Ba30 dispersion in rapeseed oil, 13 wt.\% of hazelnuts (Silvarem; France), 7.6 wt.\% of fat reduced cocoa powder (Kaoka; France;), 7.4 wt.\% of skimmed milk powder (Rochambeau; Franc;), 0.6 wt.\% of soy lecithin (Lecico GmbH; Germany) and 0.3 wt.\% of natural vanilla flavor (Artisans et Talents; France). Chocolate spreads were made by using a universal mixer / refiner conch (Lloveras, Spain) with a load capacity of $20 \mathrm{~kg}$. Figure 2 provides information on the different stages of the mixing / refining process in the conch (note that a prior manual mixing of the bamboo dispersion takes place just before incorporation in the conch). The granulometry is monitored every 30 minutes in triplicate with a micrometer (Outifrance, accuracy of $1 \mu \mathrm{m}$ ) and the refining process is stopped as soon as the grain size is less than $30 \mu \mathrm{m}$. 


\subsection{Oil release}

The dispersions of vegatal powders in rapeseed oil were prepared under manual stirring in cylindrical containers (diameter $52 \mathrm{~mm}$ ) at ambient temperature. The physico-chemical stability of the samples was monitored in triplicate from the visual estimation of the phase separation extent after a rest period of 15 minutes at $20{ }^{\circ} \mathrm{C}$ for cellulose dispersions or at $38{ }^{\circ} \mathrm{C}$ for chocolate spreads. For this purpose, the oil clearance index is defined as the ratio of the upper oil mass to the total mass of rapeseed oil in the sample (the upper oil mass is estimated from the volume of the upper oil layer and the density of rapeseed oil of about $0.91 \mathrm{~g} / \mathrm{cm}^{3}$ at $20{ }^{\circ} \mathrm{C}$ ).

\subsection{Shear experiments}

Shear oscillatory and shear flow experiments were conducted in a plate - plate geometry of diameter $40 \mathrm{~mm}$ driven by a stress-controlled rheometer (AR-G2, TA Instruments). Moving plates made of duralumin are sand-blasted (surface roughness $\approx 4 \mu \mathrm{m}$ ) to minimize wall slipping. The temperature of the sample is controlled with a Peltier unit with an accuracy of $0.1{ }^{\circ} \mathrm{C}$. After the introduction of the dispersion in the plate - plate geometry, a constant gap width of $1 \mathrm{~mm}$ is imposed.

Shear oscillations with a small strain amplitude of $0.2 \%$ are performed at a solicitation frequency of $1 \mathrm{~Hz}$ during five minutes to monitor the temporal evolution of the viscoelastic properties of the dispersion and the average of data over the last three minutes gives the storage modulus $G^{\prime}$ in $\mathrm{Pa}$.

The same configuration was used to study the flow properties of the dispersion in a continuous shear flow. After a first pre-shearing stage at $100 \mathrm{~s}^{-1}$ during 30 seconds to rejuvenate the dispersion and remove air bubbles, the sample is kept at rest during 2 minutes before 
149 imposing a decreasing shear rate from $100 \mathrm{~s}^{-1}$ down to $1 \mathrm{~s}^{-1}$ with an equilibrium time of 10 150 seconds and further data average for 20 seconds between successive acquisitions. A linear 151 scaling is observed for shear rates $10 s^{-1}<\dot{\gamma}<10^{2} s^{-1}$ when plotting $\tau^{1 / 2}$ versus $\left(\eta_{o} \dot{\gamma}\right)^{1 / 2}$ (Fig.

1524 and 6a) where $\eta_{\mathrm{o}}=0.243$ Pa.s. is the Newtonian viscosity of rapeseed oil. A Casson law $153 \tau^{1 / 2}=\tau_{o}{ }^{1 / 2}+\left(\eta_{\infty} \dot{\gamma}\right)^{1 / 2}$ often considered to describe the rheology of non-Newtonian fluids was 154 then selected to determine the yield stress $\tau_{\mathrm{o}}$ and the high shear viscosity $\eta_{\infty}=\eta_{\mathrm{r}} \eta_{\mathrm{o}}$ (or limiting 155 viscosity) of the dispersion where $\eta_{\mathrm{r}}$ is the dimensionless relative viscosity of the dispersion at 156 high shear rates (Snabre et al, 1996). The interception with the vertical axis of the best linear fit of $\left[\left(\eta_{0} \dot{\gamma}\right)^{1 / 2}, \tau^{1 / 2}\right]$ data for shear rates $10 s^{-1}<\dot{\gamma}<10^{2} s^{-1}$ gives the square root of the yield

158 stress $\tau_{\mathrm{o}}$ (dashed lines in Fig. 4 and 6a). On the other hand, the high shear viscosity $\eta_{\infty}$ of the dispersion is derived from the slope $\left(\eta_{\circ} / \eta_{\mathrm{o}}\right)^{1 / 2}$ of the same best linear regression.

\subsection{Differential Scanning Calorimetry}

161 Thermal analyses were also conducted with a differential scanning calorimeter (micro DSC VII, Setaram) to estimate the melting point of chocolate spreads made either with palm oil or a dispersion of vegetal powder in rapeseed oil. We use hermetically sealed aluminum pans of volume $0.7 \mathrm{~mL}$ for the sample and the reference oil (either palm or rapeseed oil). The melting behavior was monitored from $20{ }^{\circ} \mathrm{C}$ up to $60{ }^{\circ} \mathrm{C}$ at a heating rate of $+0.5^{\circ} \mathrm{C} / \mathrm{min}$.

\subsection{Rapeseed oil texturing}

Thirteen different vegetal powders, listed in Table 1, were added separately in rapeseed oil with a 30 wt.\% mass fraction at the ambient temperature. After manual stirring during two minutes, dispersions prepared with a powder of low cellulose content (Acacia, Pea, Chicory...) 
171

172

174

175

176

177

178

179

180

181

182

183

184

185

186

187

188

189

190

remain liquid (Table 2). On the other hand, powders with a cellulose content higher than 60 wt.\% (bamboo, wheat, oat or citrus) give rise to solid-like dispersions (Table 2).

The Figure 3 shows some 30 wt.\% dispersions after a rest period of 15 minutes and gives clear evidence of a texturing effect of the rapeseed oil for bamboo and wheat cellulose powders since the samples remain stable without any oil clearance. In the case of pea, acacia and chicory powders, the liquid-like behavior of dispersions and the settling of particles result in a noticeable phase separation with an oil clearance index in the range from $8.9 \%$ up to $54.5 \%$ after 15 minutes rest. When overturning the tubes, bamboo and wheat dispersions remain stable whereas a downward flow of the liquid-like dispersion is observed for the three other samples that exhibit a marked phase separation (right samples in Fig. 3).

These observations highlight a texturing effect of mercerized cellulose powders in rapeseed oil for a minimum cellulose content of about $60 \mathrm{wt} . \%$ and a sufficient amount of cellulose fibers, preferentially with a maximum size $L_{\max }$ higher than $100 \mu \mathrm{m}$ (Table 2). Oleogelation is indeed no more observed for either a low cellulose content less than $60 \mathrm{wt} \%$ or a weak relative proportion of cellulose fibers in the powder (Table 2).

\subsection{Impact of cellulose content}

A rheological characterization of dispersions was performed focusing on the vegetal powders with different cellulose content and 30 wt.\% mass fraction presented in Fig. 3. Considering a Casson law, the square root of the equilibrium shear stress $\tau$ is plotted as a function of the quantity $\left(\eta_{\infty} \dot{\gamma}\right)^{1 / 2}$ to extract the square root of the yield stress $\tau_{0}$ from the best linear fit of data 
for shear rates $10 \mathrm{~s}^{-1}<\dot{\gamma}<10^{2} \mathrm{~s}^{-1}$ (see paragraph 2.4 and Fig. 4). Small amplitude oscillatory

shear experiments were further conducted to measure the storage modulus $G^{\prime}$ of the dispersions. Pea, acacia and chicory cellulose powders with a low cellulose content result in dispersions with extremely low values of both the yield stress $\tau_{\mathrm{o}}$ and the storage modulus $G^{\prime}$ in accordance with the liquid-like behavior of these systems (Fig. 4 and Table 3). On the other hand, the high cellulose content in bamboo and wheat powders leads to a significant increase in both the yield stress (83.2 $\mathrm{Pa}$ and 20.2 $\mathrm{Pa}$ for bamboo and wheat cellulose dispersions, respectively, Table 3) and the storage modulus that confirms the solid-like behavior of $30 \mathrm{wt} . \% \mathrm{Ba}$ and $30 \mathrm{wt} . \% \mathrm{Wh}$ dispersions (see Fig. 3). Vegetal powders with a sufficient cellulose content thus behave as oleogelators in rapeseed oil.

\subsection{Impact of cellulose fiber size and mass fraction}

When adding gradually the vegetal powder by step of $2.5 \mathrm{wt} . \%$ in rapeseed oil, the dispersion becomes more viscous and suddenly displays a solid-like behavior for a critical mass fraction $c_{\text {yield. }}$ Table 4 gives the critical mass fraction $c_{\text {yield }}$ for several bamboo or wheat powders with a high cellulose content and different granulometries. Increasing the maximum fiber size $L_{\max }$ in the vegetal powders from $120 \mu \mathrm{m}$ up to $1500 \mu \mathrm{m}$ results in a sharp decrease of the critical mass fraction $c_{\text {yield }}$ from about 30 wt.\% down to 4 wt.\% (Table 4). Figure 5 indeed shows a good correlation between the critical mass fraction $c_{\text {yield }}$ and the maximum size $L_{\max }$ of cellulose fibers in the powder without significant influence of the botanical origin for bamboo and wheat dispersions. The oleogelation thus critically depends on the cellulose content in the vegetal powder but the extent of the texturing effect is mainly controlled by the size of cellulose fibers. 
Rheology experiments were further conducted to study the influence of the powder mass fraction in rapeseed oil when keeping constant the maximum size $L_{\max }$ of cellulose fibers. For this purpose, $\mathrm{Ba} 30$ dispersions with different powder mass fractions in the range from $0 \mathrm{wt} . \%$ up to $30 \mathrm{wt} . \%$ were prepared and analyzed either in a continuous shear flow or in a small amplitude oscillatory shear flow. Once more, Ba30 dispersions behave as Casson Non-Newtonian fluids (Fig. 6a) with a marked increase in the yield stress $\tau_{\mathrm{o}}$ for a powder mass fraction $c$ in rapeseed oil higher than 12 wt.\% (Fig. 6b). The storage modulus $G^{\prime}$ further exhibits an exponential increase with the mass fraction $c$ of Ba30 powder added in rapeseed oil (Fig. 6b).

\subsection{Texturation of chocolate spreads with cellulose fibers}

The substitution of palm oil with an oleogel in chocolate spreads represents a challenge (Martins et al., 2020; Pehlivanoglu et al., 2017). Some authors proposed alternatives to palm oil either by using fats like red palm olein or oil mixtures for an enrichment in unsaturated triglycerides (El-Haddad et al., 2011; Manzocco et al., 2014). More recently, the partial replacement of palm oil with oleogels made with monoglycerides and waxes (beewax and propolis) opens encouraging perspectives in the formulation of new chocolate spreads (Fayaz et al., 2017).

From the present work, cellulose fibers can be a potential means of texturing an edible oil in a food liquid material and help to reduce the saturated fat content while increasing fiber intake. A chocolate spread prepared with palm oil was chosen as a reference product since palm oil rich in saturated fatty acids is widely used in semi-solid food products at ambient temperature. the flowchart of processing in Fig. 2. The same protocol was repeated by replacing the entire 234 amount of palm oil with a rapeseed oil of higher fluidity. The limiting viscosity and the yield 
stress of chocolate spreads were determined as previously from a Casson plot of $\tau^{1 / 2}$ versus $\left(\eta_{0} \dot{\gamma}\right)^{1 / 2}$. Unsurprisingly, the chocolate spread made with rapeseed oil displays both a lower yield stress $\tau_{0} \approx 220.4 \mathrm{~Pa}$ and a lower limiting viscosity $\eta_{\infty} \approx 25.6 \mathrm{~Pa}$.s. compared to the values $\tau_{\mathrm{o}} \approx 283 \mathrm{~Pa}$ and $\eta_{\infty} \approx 50.5 \mathrm{~Pa}$.s. for the equivalent product made with palm oil (black and grey solid squares in Fig. 7).

A Ba30 dispersion with a mass fraction of bamboo vegetal powder in rapeseed oil ranging from $5 \mathrm{wt} . \%$ up to $30 \mathrm{wt} . \%$ was used in place of pure oil to test the texturing effect of cellulose fibers in chocolate spreads. Ba30 dispersions were prepared and mixed at ambient temperature prior to conching. The Ba30 powder is chosen in preference to the wheat powder for nonallergenicity reasons. Besides, the Ba30 powder with shorter fibers was considered here in the hope to reduce any mechanical degradation of fibers during the refining process.

246 The rheology of chocolate spreads made with Ba30 dispersions obeys once again a Casson247 type behavior. Therefore, the yield stress $\tau_{\mathrm{o}}$ and the high shear viscosity $\eta_{\infty}$ of chocolate spreads 248 were determined from the best linear fit of $\left[\left(\eta_{0} \dot{\gamma}\right)^{1 / 2}, \tau^{1 / 2}\right]$ data for shear rates

$24910 \mathrm{~s}^{-1}<\dot{\gamma}<10^{2} \mathrm{~s}^{-1}$. Figure 7 clearly shows a significant increase in both the yield stress $\tau_{0}(c)$

250 and the limiting viscosity $\eta_{\infty}(c)$ of the chocolate spread for a Ba30 mass fraction in rapeseed oil 251 above 12 wt.\%. Such a threshold is reminiscent from the solid-like behavior of Ba30 dispersions 252 which requires a mass fraction of Ba30 powder in rapeseed oil higher than 12 wt.\% (Fig. 6b). 253 Furthermore, a mass fraction of Ba30 powder in the range from $20 \mathrm{wt} . \%$ up to $30 \mathrm{wt} . \%$ is enough 254 to recover the rheological properties of the chocolate spread made with palm oil (Fig. 7). 
The thermal stability of chocolate spreads was further investigated after the production. For this purpose, the melting range of palm oil was previously determined by DSC and identified as the wide heat peak observed around $38^{\circ} \mathrm{C}$ (not shown). Therefore, chocolate spreads samples were stored at $38^{\circ} \mathrm{C}$ in static conditions during 3 weeks and the oil clearance index was estimated after the rest period.

The chocolate spread made with palm oil appears as unstable when stored at $38^{\circ} \mathrm{C}$ with an oil clearance index of $53+/-11 \%$ (Fig. 8). A close result was obtained for the product made with rapeseed oil only $(50+/-5 \%$, Fig. 8$)$. In the case of chocolate spreads made with a Ba30 dispersion, the oil clearance index significantly decreases for a powder mass fraction in excess of $10 \mathrm{wt} . \%$ until a complete thermal stabilization of the product for a mass fraction of $30 \mathrm{wt} . \%$ (Fig. 8). Such results confirm that (i) the melting of triglycerides at $38^{\circ} \mathrm{C}$ contributes to the unstable thermal behavior of the chocolate spread made with palm oil and (ii) the use of cellulose fibers in rapeseed oil provides both greater thermal stability and longer shelf life as a result of an oleogelation effect and a lower content in saturated fatty acids.

To compare the nutritional qualities of chocolate spreads, a dedicated software was used (Foodworks®). The obtained data indicate close energetic values for both products either made with palm oil or a $30 \mathrm{wt} . \% \mathrm{Ba}$ dispersion in rapeseed oil. As expected, a marked decrease of the saturated fat content, in favor of unsaturated ones, is observed for chocolate spreads made with rapeseed oil $(\approx 11.6 \mathrm{wt} . \%$ and $\approx 2.6 \mathrm{wt} . \%$ for the saturated fat content in the chocolate spread made with palm oil or a $30 \mathrm{wt} \%$ Ba30 dispersion in rapeseed oil, respectively, Fig. 8). The use of $\mathrm{Ba} 30$ powder as an oleogelator further significantly increases the fiber content $\approx 7 \mathrm{wt} . \%$ in the chocolate spread made with a 30\% wt.\% Ba30 dispersion in rapeseed oil (compared with a fiber content of only $1.3 \mathrm{wt} . \%$ for a chocolate spread made with palm oil). 
As a consequence, cellulose fibers in rapeseed oil are efficient oleogelators to produce a solid-

like texture with a limited number of steps in the fabrication process of the chocolate spread through a direct dispersion of the vegetal powder in an edible oil at ambient temperature. Solidlike dispersions of cellulose fibers can thus be used in chocolate spreads production without any additives to improve both the rheological properties and the nutritional qualities of food products.

\section{Discussion}

The texturing of an edible oil requires a suitable balance between the affinity of the oleogelators for the solvent and sufficient insolubility in the oil phase (Patel, 2018). In other terms, the hydrophilic-lipophilic balance controls the oleogelation mechanism in the same way as the HLB of emulsifiers is a key control parameter in the formulation of stable emulsions. In this context, the texturing of the oil phase is mainly governed by solute-solute or solute-solvent interactions through the self-assembly of oleogelators to form a 3-dimensional network entrapping the oil in a solid-like structure. The supramolecular structures are then mainly stabilized by Hydrogen bonds and/or Van der Walls attractive interactions giving rise to a physical gel.

Native cellulose or cellulose $\mathrm{I}$ is a ligno-cellulosic material of biological origin. The microfibrils consist of highly ordered molecules of cellulose (crystalline hydrophobic region) coated with non-cellulosic constituents as lignins and hemicelluloses (flexible amorphous region more soluble in water) (Hon, 1994; Megashah, 2018)

Mercerized or regenerated cellulose (cellulose II) is obtained after an ionic treatment of the native cellulose, sometimes followed with a bleaching and/or a mechanical treatment of the 
microfibrils (Kleppe, 1970; Hon, 1994; Li et al, 2018). The irreversible mercerization process lowers the amorphous hemicelluloses and lignins content and further results both in a higher crystallinity and a mechanical degradation of cellulose bundles. One may thus expect a higher affinity of mercerized cellulose fibers for oil and the emergence of amphiphilic properties (Bergenstråhle et al., 2010; Lindman et al., 2010; Medronho et al., 2012).

When dissolving vegetal powders in water, a shear-dilatant (or shear-thickening) behavior of the dispersion was obtained when the mass fraction of powder in water exceeds a critical mass fraction $c_{\text {dilatant }}$. The formation of cracks when stirring the concentrated dispersion indeed confirms the shear-dilatant behavior of vegetal powders in water (Brown et al, 2014). The jamming transition under stirring likely results from the swelling in water of the hydrophilic amorphous constituents of vegetal powders.

On the other hand, concentrated dispersions of vegetal powders in rapeseed oil display a shear-thinning with a yield stress behavior (Fig. 4 and 6a) without any shear-dilatancy or shearinduced cracks when stirring. Such a behavior reflects a good lubrication in oil and some oil solvation of the hydrophobic crystalline regions of cellulose fibers. The affinity of the hydrophobic crystalline regions of cellulose fibers for oil could then favor attractive interactions between cellulose microfibrils.

To ascertain these conjectures, we have observed with a light microscope the interfacial front between the liquid phase (water or rapeseed oil) and a concentrated dispersion of vegetal powder prepared with a mass fraction just above the critical mass fraction $c_{\text {dilatant }}$ for shear - thickening in water or the critical mass fraction $c_{\text {yield }}$ for a yield stress behavior in rapeseed oil (see table 4). For this purpose, a drop of liquid (water or rapeseed oil) is deposited on a glass slide very close to a small drop of the concentrated dispersion before gently covering with a glass coverslide and 
further observation of the interfacial front region. In the case of dispersions in water (left pictures in Fig. 9), the front spreads out over very large distances (some millimeters) since the cellulose fibers display no attractive interactions and are free to diffuse. On the other hand, the front appears as more or less sharp in rapeseed oil (right pictures in Fig. 9) likely because of some weak attractive interactions between cellulose fibers in oil as conjectured above. As remarked by Martins et al (2018), the entanglement of polymers in an edible oil also represents a possible mechanism of oleogelation. The $10 \mathrm{wt} . \%$ Ba400 dispersion with long sized cellulose fibers $\left(L_{\max }\right.$ $\approx 1000 \mu \mathrm{m}$ for Ba400 powder, see Table 2) indeed display a sharp interfacial front in rapeseed oil as a consequence of fiber entanglement (bottom right picture in Fig. 9). In the case of short sized fibers in rapeseed oil, the front becomes somewhat less sharp and the entanglement of fibers appears as less marked, especially for the $30 \mathrm{wt} . \%$ Ba30 dispersion of vegetal powder in rapeseed oil ( $L_{\max } \approx 120 \mu \mathrm{m}$ for Ba30 powder, top right picture in Fig. 9). Weak attractive interactions between cellulose fibers thus explain the structuring of rapeseed oil. However, the entanglement of cellulose fibers becomes the dominant mechanism of oleogelation with a marked increase in the yield stress of dispersions when the vegetal powder contains long sized fibers. A much lower critical mass fraction $c_{\text {yield }}$ of vegetal powder is then required for a solid-

340 like behavior of the dispersion when the maximum size $L_{\max }$ of cellulose fiber exceeds $500 \mu \mathrm{m}$ 341 (Figure 5).

Apart from the impact of fiber size and as a prime condition, oleogelation further requires a 343 minimum cellulose content of about $60 \mathrm{wt} . \%$ in the vegetal powder. No texturing of the rapeseed 344 oil was indeed observed with vegetal powders that display a low cellulose content associated 345 with either a dominant proportion of hydrophilic amorphous constituents or a complete lack of 346 cellulose fibers as in the acacia or chicory powders (Table 2). 


\section{Conclusion}

The rheology of dispersions of mercerized cellulose in rapeseed oil was analyzed as a function of the botanical origin, the granulometry and the mass fraction of powder. A low amount of cellulose as well as non-fibrous particles and / or hydrophilic constituents undermines the oleogelation efficiency of vegetal powders. On the other hand, a texturing of the edible oil without any heating of the dispersion was observed for a minimum cellulose content of about 60 wt.\% in the vegetal powders.

A solid-like and a shear-thinning behavior of the dispersion was also observed and quantified for a minimum mass fraction $c_{\text {yield }}$ of cellulose powder in rapeseed oil. The yield stress $\tau_{\mathrm{o}}$ and the equilibrium storage modulus $G^{\prime}$ of the dispersion increase with the maximum size $L_{\max }$ of fibers in the powder. Microscopic observations of the more or less sharp front between the oil phase and the concentrated solid-like dispersion give evidence of both weak fiber attractive interactions and fiber entanglement (when the fiber size $L_{\max }$ exceeds $500 \mu \mathrm{m}$ ) at the origin of the oleogelation mechanism. Fiber entanglement then results in a marked increase in the oleogelation efficiency. The use of cellulose fibers as oleogelators without any prior thermal treatment of the polymer was demonstrated and represents a remarkable breakthrough in the field. Study of the viscoelastic properties of the cellulose dispersion in terms of frequency and amplitude of the oscillating strain would bring additional knowledge about the oleogelation mechanism and should be addressed in a future work.

An innovative strategy using a dispersion of cellulose fibers in rapeseed oil was finally proposed to produce a chocolate spread with higher nutritional qualities. The chocolate spread prepared with a dispersion of cellulose fibers in rapeseed oil in place of palm oil display close 
rheological properties and a high thermal stability when stored at $38{ }^{\circ} \mathrm{C}$. Finally, a chocolate

370 spread prepared with a dispersion of cellulose fibers in rapeseed oil has improved nutritional

371 qualities (lower saturated fat content, higher content in unsaturated fat and vegetal fibers) which

372 paves the way to future developments of food products with health benefits.

\section{Acknowledgements}

374 The authors are grateful for the relevance of the referee's comments. The authors also

375 acknowledge the Nouvelle-Aquitaine Regional Council as well as the Délégation Régionale à la

376 Recherche et à la Technologie (DRRT, Nouvelle Aquitaine) for the financial support. The

377 authors also thank Martine Crepin and Caroline Lair for useful technical discussions. 


\section{References}

Bergenstråhle, M., Wohlert, J., Himmel, M.E., \& Brady, J.W. (2010). Simulation studies of the insolubility of cellulose. Carbohydrate. Research. 345, 2060-2066. https://doi.org/10.1016/j.carres.2010.06.017

Brown, E, Jaeger, H.M (2014). Shear thickening in concentrated suspensions: phenomenology, mechanisms, and relations to jamming. Reports on Progress in Physics. 77(4), 046602. doi: $10.1088 / 0034-4885 / 77 / 4 / 046602$

Choi, H-M \& Moreau, J.P. (1993). Oil sorption of various sorbents studied by sorption capacity measurement and environmental scanning electron microscopy. Microscopy Research and Technique, 25, 447-455. https://doi.org/10.1002/jemt.1070250516

Davidovich-Pinhas, M., Barbut, S., \& Marangoni, A.G. (2015). The gelation of oil using ethyl cellulose. Carbohydrate Polymers, 117, 869-878. https://doi.org/10.1016/j.carbpol.2014.10.035

El-Hadad, N.N.M., Youssef, M., Abd El-Aal, M.H., \& Abou-Gharbia, H.H. (2011). Utilisation of red palm olein in formulating functional chocolate spread. Food Chemistry, 124, 285-290. https://doi.org/10.1016/j.foodchem.2010.06.034

Fayaz, G., Goli, S.A.H., Kadivar, M., Valoppi, F., Barba, L., Calligaris, S., \& Nicoli, M.C. (2017). Potential application of pomegranate seed oil oleogels based on monoglycerides, beewax and propolis was as partial substitute of palm oil in functional chocolate spread. Food Science and Technology, 86, 523-529. https://doi.org/10.1016/j.lwt.2017.08.036 
Ferreira Chaves, K., Barrera-Arellano, D., \& Badan Ribeiro, A.P. (2018). Potential application of lipid organogels for food industry. Food Research International. 105, 863-872. https://doi.org/10.1016/j.foodres.2017.12.020

Hon, D. N-S. (1994). Cellulose: a random walk along its historical path, Cellulose, 1, 1-25.

Hwang, H-S. (2020). A critical review on structures, health effects, oxidative stability, and sensory properties of oleogels. Biocatalysis and Agricultural Biotechnology. 26, 101657. https://doi.org/10.1016/j.bcab.2020.101657

Jiang, Y., Liu, L., Wang, B., Sui, X., Zhong, Y., Zhang, L., Mao, Z., \& Xu, H. (2018). Celluloserich oleogels prepared with an emulsion-templated approach. Food Hydrocolloids. 77, 460-464. https://doi.org/10.1016/j.foodhyd.2017.10.023

Khatun, R., Reza, M.I.H., Moniruzzaman, M., \& Yaakob, Z. (2017). Sustainable oil palm industry: The possibilities. Renewable and Sustainable Energy Reviews, 76, 608-619. https://doi.org/10.1016/j.rser.2017.03.077

Kleppe, P.J. (1970). Kraft pulping. Tappi. 53, 1, 35-47.

Li, Y., Wang, J., Liu, X., Zhang, S. (2018). Towards a molecular understanding of cellulose dissolution in ionic liquids: anion/cation effect, synergic mechanism and physicochemical aspects. Chemical Science. 9, 4027-4043. doi: 10.1039/c7sc05392d

Likon, M., Remskar, M., Ducman, V., \& Svegl, F. (2013). Populus seed fibers as a natural source for production of oil super absorbants. Journal of Environmental Management, 14, 158167. doi: $10.1016 /$ j.jenvman.2012.03.047 
417 Lindman, B., Karlström, G., \& Stigsson, L. (2010). On the mechanism of dissolution of 418 cellulose. Journal of Molecular $\quad$ Liquids. $\quad 156, \quad 76-81$. 419 https://doi.org/10.1016/j.molliq.2010.04.016

420 Manzocco, L., Calligaris, S., Camerin, M., Pizzale, L., \& Nicoli, M.C. (2014), Prediction of 421 firmness and physical stability of low-fat chocolate spreads, Journal of Food Engineering, 126, 422 120-125. https://doi.org/10.1016/j.jfoodeng.2013.10.042

Martins, A.J., Vicente, A.A., Cunha, R.L., \& Cerqueira, M.A. (2018), Edible oleogels: an opportunity for fat replacement in foods, Food \& Function, 9, 758-773. doi: 10.1039/c7fo01641g

Martins, A.J., Vicente, A.A., Pastrana, L.M., \& Cerqueira, M.A. (2020), Oleogels for 426 development of health-promoting food products, Food Science and Human Wellness, 9, 1, 31-39. https://doi.org/10.1016/j.fshw.2019.12.001

Medronho, B., Romano, A., Miguel, M.G., Stigsson, L., \& Lindman, B. (2012). Rationalizing cellulose (in)solubility: reviewing basic physicochemical aspects and role of hydrophobic interactions. Cellulose 19, 581-587. https://doi.org/10.1007/s10570-011-9644-6

Megashah, L.N., Ariffin, H., Zakaria, M.R., Hassan, M.A. (2018). Properties of cellulose extract 432 from different types of oil palm biomass, IOP Conference Serie: Materials Science and 433 Engineering, 368, 012049. doi: 1088/1757-899X/368/1/012049

434 Mezzenga, R. (2011). Protein-templated oil gels and powders. Edible oleogels: Structure and 435 health implications, 271-293. https://doi.org/10.1016/B978-0-9830791-1-8.50015-2.

436 Patel, A. R., \& Dewettinck, K. (2016). Edible oil structuring: an overview and recent updates. 
Patel, A.R. (2018). Oil structuring: concepts, overview and future perspectives In: Edible oil structuring: concepts, methods and applications. 3-21. RSC London. ISBN: 978-1-78262-829-3

Patel, A.R., Nicholson, R.A., \& Marangoni, A.G. (2020). Applications of Fat mimetics for the replacement of saturated and hydrogenated fat in food products. Current Opinion in Food Science, 33, 61-68. https://doi.org/10.1016/j.cofs.2019.12.008

Pehlivanoglu, H., Demirci, M., Toker, O.S., Konar, N., Karasu, S., \& Sagdic, O. (2017). Oleogels, a promising structured oil for decreasing saturated fatty acid concentrations: production and food-based applications. Critical Reviews in Food Science and Nutrition. 58, 8, 1330-1341. https://doi.org/10.1080/10408398.2016.1256866

Scholten, E. (2019). Edible oleogels: how suitable are proteins as a structurant? Current opinion in Food Science. 27, 36-42. https://doi.org/10.1016/j.cofs.2019.05.001

Singh, V., Kendall, R.J., Hake, K., \& Ramkumar, S. (2013). Crude oil sorption by raw cotton. Industrial \& Engineering Chemistry Research, 52, 6277-6281. https://doi.org/10.1021/ie4005942

Singh, A., Auzanneau, F-I., \& Rogers, M.A. (2017). Advances in edible oleogel technologies A decade in review. Food Research International, 97, 307-317. https://doi.org/10.1016/j.foodres.2017.04.022

Snabre, P. \& Mills, P. (1996). Rheology of weakly flocculated suspensions of rigid particles, Journal de Physique III, 6, 12, 1811-1834. https://doi.org/10.1051/jp3:1996215

Thilagavathi, G., Praba karan, C., \& Das, D. (2018). Oil sorption and retention capacities of thermally hybrid nonwovens prepared from cotton, kapok, milkweed and polypropylene fibers. 
459 https://doi.org/10.1016/j.jenvman.2018.04.107

460 Wahi, R., Chuah, L.A., Choong, T.S.Y, Ngaini, Z., \& Nourouzi, M.M. (2013). Oil removal from 461 aqueous state by natural fibrous sorbent: an overview. Separation and Purification Technology, 462 113, 51-63. https://doi.org/10.1016/j.seppur.2013.04.015

463 Zhu, X., Lundberg, B., Cheng, Y., Shan, L., Xing, J., Peng, P., Chen, P., Huang, X., Li, D., \& 464 Ruan, R. (2017). Effect of high-pressure homogeneization on the flow properties of citrus peel 465 fibers. Journal of Food Process Engineering, e12659. https://doi.org/10.1111/jfpe.12659 


\section{Figure captions}

Figure 1: Microscopic observations of $0.1 \mathrm{wt} \%$ diluted dispersions in rapeseed oil. $\mathrm{x} 4$ magnification for Ba30, Ba90, Wh90, Ba400 and x20 magnification for Pe200, Ch180 (light microscope Nikon Eclipse E600 POL).

Figure 2: Flowchart of the processing of chocolate spreads made in a universal mixer / refiner conch either with palm oil or a 30 wt.\% Bamboo Ba30 / Rapeseed oil dispersion.

Figure 3: (a) Visual observations of 30 wt.\% dispersions (Wheat90, Bamboo90, Pea200, Acacia and Chicory180 from left to right) in rapeseed oil after manual mixing and a rest period of 15 minutes with indication of the oil clearance index in percent of the oil volume in the dispersion. The two left 30 wt.\% dispersions of Wh90 and Ba90 display negligible oil clearance (a) and appear as solid-like when the tube is overturned (b) while the three right samples show a significant oil clearance (a) and a downward flow after tube inversion (b).

Figure 4: Square root of the shear stress $\tau$ versus the square root of the product of rapeseed oil viscosity $\eta_{o}$ and shear rate $\dot{\gamma}$ for several $30 \mathrm{wt}$.\% dispersions. Considering a Casson law, the interception of the vertical axis with a linear fit of $\left[\left(\eta_{o} \dot{\gamma}\right)^{1 / 2}, \tau^{1 / 2}\right]$ data for shear rates 10 $\mathrm{s}^{-1}<\dot{\gamma}<100 \mathrm{~s}^{-1}$ (dashed lines) gives the square root of the yield stress $\tau_{o}$. The horizontal arrow shows the square root of the yield stress $\tau_{o}$ for the $30 \mathrm{wt} . \% \mathrm{Ba} 90$ dispersion.

Figure 5: Critical mass fraction $c_{\text {yield }}$ necessary for a solid - like behavior of $30 \mathrm{wt} . \%$ dispersions in rapeseed oil versus the maximum size $L_{\max }$ of cellulose fibers in vegetal powders Wh (blue circles) and $\mathrm{Ba}$ (black circles) (data from Table 4).

Figure 6: (a) Square root of the shear stress $\tau$ versus the square root of the product of rapeseed oil viscosity $\eta_{o}$ and shear rate $\dot{\gamma}$ for Ba30 dispersions with different mass fraction $c$ of vegetal powder in rapeseed oil. (b) Yield stress $\tau_{\mathrm{o}}$ (black circles) and storage modulus $G^{\prime}$ (grey solid squares) of $\mathrm{Ba} 30$ dispersions versus the mass fraction $c$ of vegetal powder in rapeseed oil (b). Dashed lines in (a) are best linear fits of $\left[\left(\eta_{o} \dot{\gamma}\right)^{1 / 2}, \tau^{1 / 2}\right]$ data for shear rates $10 \mathrm{~s}^{-1}<\dot{\gamma}<100 \mathrm{~s}^{-1}$. The horizontal arrow in (a) shows the square root of the yield stress $\tau_{\mathrm{o}}$ for the 25 wt.\% Ba30 dispersion. Black and grey dashed curves in (b) are only guides for the eye. Measurements of $\tau_{\mathrm{o}}$ and $G^{\prime}$ with a maximal standard deviation of $10 \%$.

Figure 7: Yield stress $\tau_{o}$ (black solid circles) and high shear rate viscosity $\eta_{\infty}$ (grey solid circles) of chocolate spreads as a function of the mass fraction $c$ of bamboo Ba30 powder added in rapeseed oil before incorporation in the conch. The black solid square and the grey solid square are respectively for the yield stress $\tau_{o}$ and the limiting viscosity $\eta_{\infty}$ of chocolate spreads made with palm oil. Dashed lines are only guides for the eye. Measurements of $\tau_{\mathrm{o}}$ and $\eta_{\infty}$ with a maximum standard deviation of $10 \%$.

Figure 8: Oil clearance index of chocolate spreads after storage at $38^{\circ} \mathrm{C}$ for three weeks. The chocolate spread is either made with palm oil, rapeseed oil, or a dispersion of bamboo Ba30 in rapeseed oil with respective mass fraction $c=10 \mathrm{wt} . \%, 20 \mathrm{wt} . \%$ or $30 \mathrm{wt} . \%$. 
Figure 9: Light microscopy observations of the interfacial front between the liquid phase (water for the left pictures or rapeseed oil for the right ones) and a concentrated dispersion of either bamboo $\mathrm{Ba}$ or wheat $\mathrm{Wh}$ powders in water (left pictures) or in rapeseed oil (right pictures). Dispersions were prepared with a mass fraction of vegetal powder just above the critical mass fraction $c_{\text {thichening }}$ for shear - thickening in water or the critical mass fraction $c_{\text {yield }}$ for a yield stress behavior in rapeseed oil (see table 4). A drop of liquid (water or rapeseed oil) is deposited on a glass slide very close to a small drop of the concentrated dispersion before gently covering with a glass coverslide and further observation of the interfacial front region. 
Table 1. General information on mercerized cellulose powders: botanical source, provider, powder purity, sieving size of powders, molecular composition obtained from a van Soest analysis ( $\mathrm{C}$ for cellulose with a standard deviation $+/-5 \%$, HC for hemicelluloses with a standard deviation $+/-5 \%$ and $\mathrm{L}$ for lignins with a standard deviation $+/-7.5 \%$ ). The dashed line separates samples with either high or low cellulose content. The bamboo Bam powder marked with an asterisk was not thoroughly investigated but texturing of rapeseed oil was observed.

\begin{tabular}{|c|c|c|c|c|c|c|}
\hline Botanical source & Provider & $\begin{array}{c}\text { Purity } \\
\%\end{array}$ & $\begin{array}{c}\text { Sieving size } \\
\mu \mathrm{m}\end{array}$ & $\begin{array}{c}\mathbf{C} \\
\text { wt. } \\
\%\end{array}$ & $\begin{array}{c}\text { HC } \\
\text { wt. } \\
\%\end{array}$ & $\begin{array}{c}\mathbf{L} \\
\text { wt. } \\
\%\end{array}$ \\
\hline Bamboo Bam* & RETTENMAIER & 97 & 200 & 84.2 & 9.4 & 0.5 \\
\hline Wheat Wh & JELU-WERK & 98 & $\begin{array}{c}30,90,150 \\
400,1500\end{array}$ & 80.3 & 12.1 & 0.6 \\
\hline Bamboo $B a$ & JELU-WERK & 98 & $\begin{array}{c}30,90,200 \\
400,1000\end{array}$ & 79.9 & 12.5 & 0.9 \\
\hline Oat $O a^{*}$ & JELU-WERK & 98 & $\begin{array}{c}30,150 \\
400,1500\end{array}$ & 69.4 & 14.1 & 6.4 \\
\hline Citrus Cit* & CEAMSA & 91 & 200 & 64.0 & 13.0 & 13.8 \\
\hline Carrot $\mathrm{Ca}$ & ID-FOOD & 85 & 500 & 24.2 & 31.7 & 3.0 \\
\hline Wheat Whe & HI-FOOD & 57 & 600 & 23.4 & 18.0 & 1.3 \\
\hline Pea $P e$ & ROQUETTE & 50 & 200 & 15.3 & 13.1 & 1.5 \\
\hline Soja So & TRIBALLAT & 45 & 400 & 10.8 & 8.2 & 1.8 \\
\hline Wheat bran WhB & ID-FOOD & 40 & 200 & 8.5 & 26.9 & 3.8 \\
\hline Potato $P o$ & POTEX & 65 & No sieving & 7.3 & 13.7 & 16.1 \\
\hline Acacia $A c$ & NEXIRA & 90 & No sieving & 0 & 0.1 & 0.5 \\
\hline Chicory $C h$ & BENEO & 85 & 180 & 0 & 0 & 0.5 \\
\hline
\end{tabular}


Table 2: Maximum size $L_{\max }$ of fibers and maximum diameter $D_{\max }$ of non-fibrous globular particles in sieved mercerized powders when detectable. The symbols (-), (- -) and (- - -) indicates progressive smaller relative proportions of fibers or globular particles in the sample. The two right columns display the cellulose content and a qualitative information about either the solid-like or the liquid-like behavior of dispersions in rapeseed oil. The dashed line separates samples with either high or low cellulose content.

\begin{tabular}{c||c|c|c|c}
\hline Powder & $\begin{array}{c}\text { Fiber size } \boldsymbol{L}_{\text {max }} \\
\text { in } \boldsymbol{\mu m}\end{array}$ & $\begin{array}{c}\text { Particle size } \boldsymbol{D}_{\text {max }} \\
\text { in } \boldsymbol{\mu m}\end{array}$ & $\begin{array}{c}\text { Cellulose } \\
\text { content } \\
\text { in } \%\end{array}$ & $\begin{array}{c}\text { Visual } \\
\text { texture }\end{array}$ \\
\hline Bam200 & 800 & $150(-)$ & 84.2 & Solid \\
Wh90 & 300 & $150(-)$ & 80.3 & Solid \\
Wh150 & 400 & $150(-)$ & 80.3 & Solid \\
Wh400 & 1100 & $150(--)$ & 80.3 & Solid \\
Wh1500 & 1500 & No & 80.3 & Solid \\
Ba30 & 120 & $100(-)$ & 79.9 & Solid \\
Ba90 & 350 & $100(--)$ & 79.9 & Solid \\
Ba200 & 800 & $150(--)$ & 79.9 & Solid \\
Ba400 & 1000 & $100(--)$ & 79.9 & Solid \\
Oa30 & 150 & $100(-)$ & 69.4 & Solid \\
Oa400 & 1000 & 200 & 69.4 & Solid \\
Cit200 & $400(-)$ & 500 & 64 & Solid \\
Ca500 & $50(--)$ & 80 & 24.2 & Liquid \\
Whe600 & $100(--)$ & 80 & 23.4 & Liquid \\
Pe200 & $30(--)$ & 150 & 15.3 & Liquid \\
So400 & $50(--)$ & 150 & 10.8 & Liquid \\
Whb200 & $150(---)$ & 500 & 8.5 & Liquid \\
Po & No & 80 & 7.3 & Liquid \\
Ac & No & 80 & 0 & Liquid \\
Ch180 & No & & 0 & Liquid \\
\hline
\end{tabular}


Table 3: Yield stress $\tau_{\mathrm{o}}$ and storage modulus $G^{\prime}$ of $30 \% \mathrm{wt} \%$ dispersions in rapeseed oil. The two right columns indicate the cellulose content and the maximum size $L_{\max }$ of fibers in the vegetal powders. Measurement of $\tau_{\mathrm{o}}$ and $\mathrm{G}^{\prime}$ with a standard deviation of $10 \%$.

\begin{tabular}{l|c|c|c|c}
\hline \multicolumn{1}{c|}{ Sample } & $\tau_{\mathbf{0}}$ in Pa & $\boldsymbol{G}^{\prime}$ in Pa & $\begin{array}{c}\text { Cellulose } \\
\text { content } \\
\text { in wt. } \%\end{array}$ & $\begin{array}{c}\text { Fiber size } \\
\boldsymbol{L}_{\text {max }} \\
\text { in } \boldsymbol{\mu m}\end{array}$ \\
\hline Wheat Wh90 & 83.18 & 218 & 80.3 & 300 \\
Bamboo Ba90 & 20.16 & 1110 & 79.9 & 350 \\
Pea Pe200 & 0.009 & 0.18 & 15.3 & 30 \\
Acacia Ac & 0.093 & 0.94 & 0 & No \\
Chicory Ch180 & 0.0053 & 0.31 & 0 & No \\
\hline
\end{tabular}


Table 4: Influence of the maximum size $L_{\max }$ of cellulose fibers on the critical mass fraction $c_{\text {yield }}$ necessary for a solid - like behavior of dispersions in rapeseed oil.

\begin{tabular}{c|c|c}
\hline Sample & $\begin{array}{c}\text { Fiber size } \boldsymbol{L}_{\max } \\
\text { in } \boldsymbol{\mu m}\end{array}$ & $\begin{array}{c}\text { Critical mass } \\
\text { fraction } \text { c }_{\text {yield }} \text { in wt. \% }\end{array}$ \\
\hline Bamboo Ba30 & 120 & 28 \\
Bamboo Ba90 & 350 & 26 \\
Bamboo Ba200 & 800 & 13 \\
Bamboo Ba1000 & 1300 & 8 \\
\hline Wheat Wh30 & 120 & 30 \\
Wheat Wh150 & 400 & 23 \\
Wheat Wh400 & 1100 & 9 \\
Wheat Wh1500 & 1500 & 4 \\
\hline
\end{tabular}


Table 5: Nutritional values of chocolate spreads made either with palm oil or with a $30 \mathrm{wt} . \%$ Ba30 dispersion in rapeseed oil. All content values are expressed in wt.\% and were obtained with the Foodworks ${ }^{\circledR}$ dedicated software.

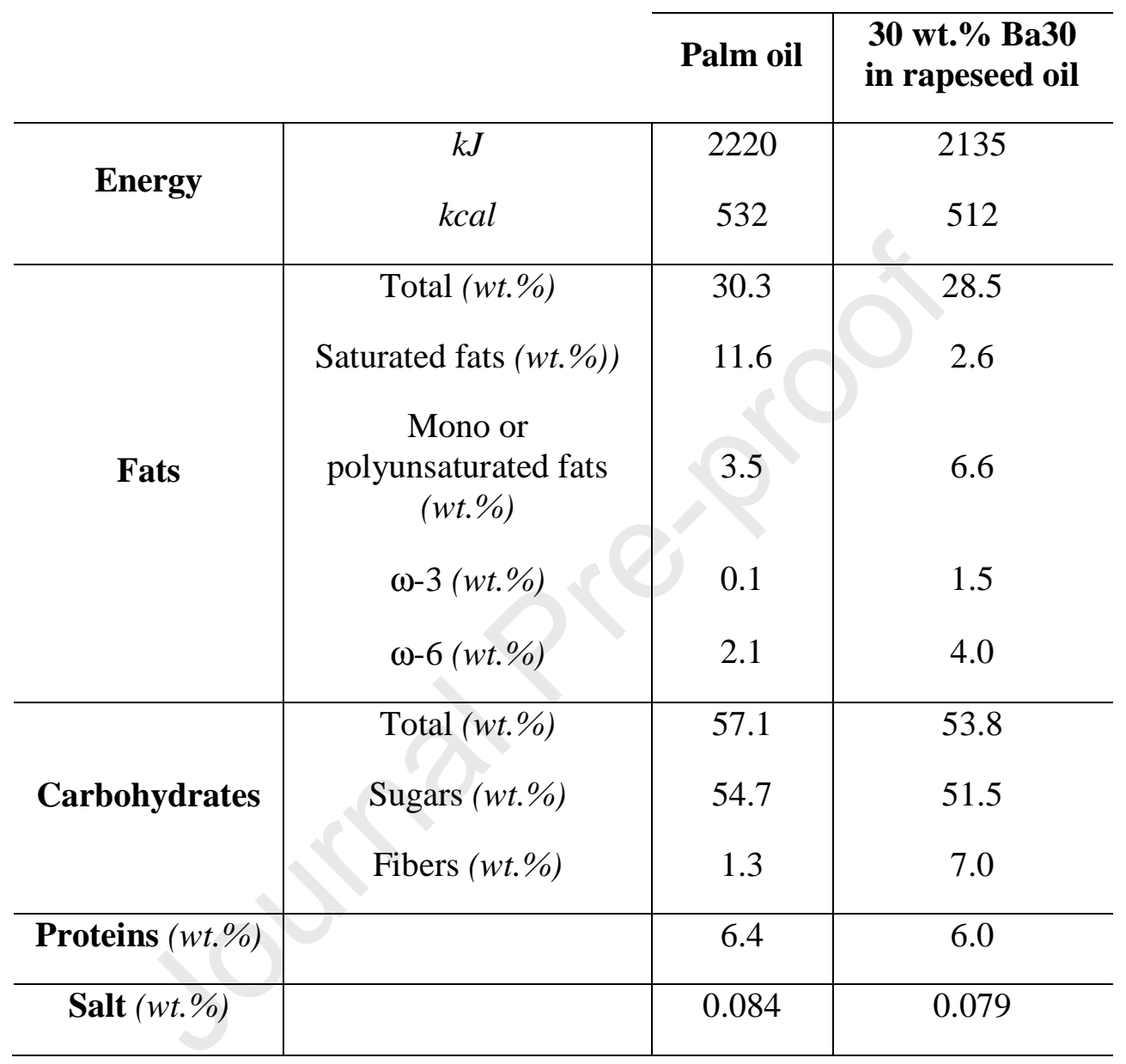




\section{Figure 1}
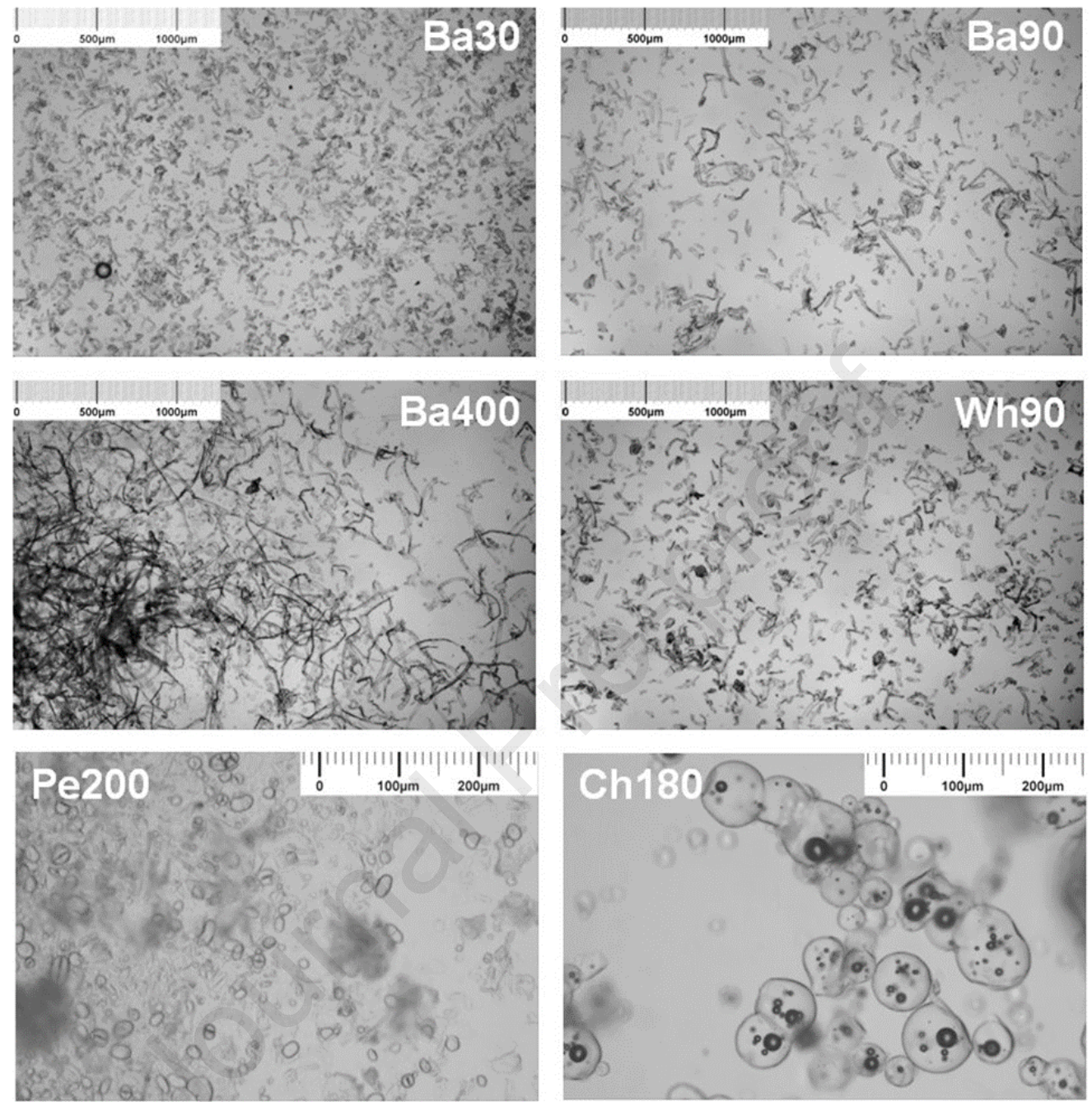
Figure 2

\section{Conching time}

(min)

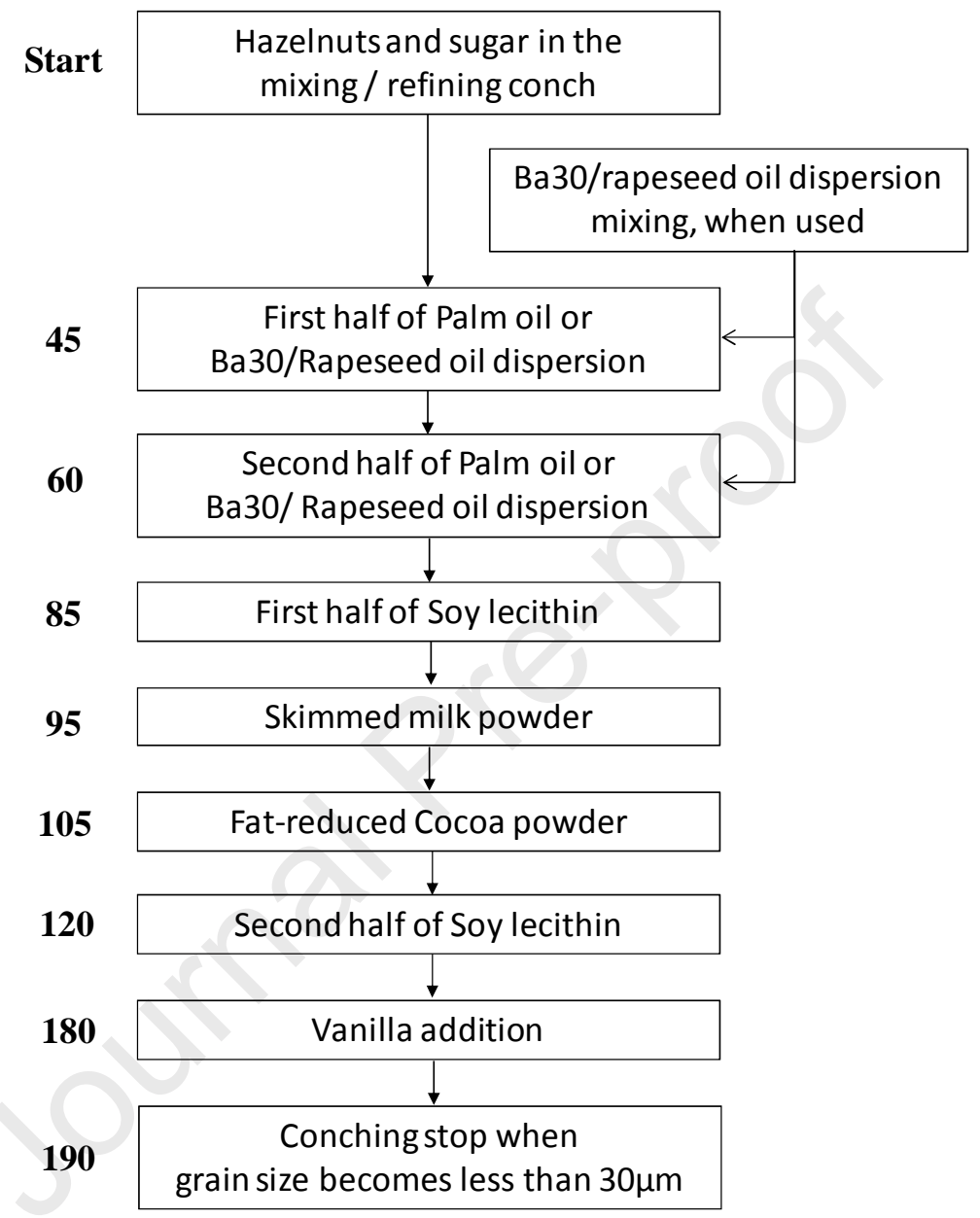


Figure 3

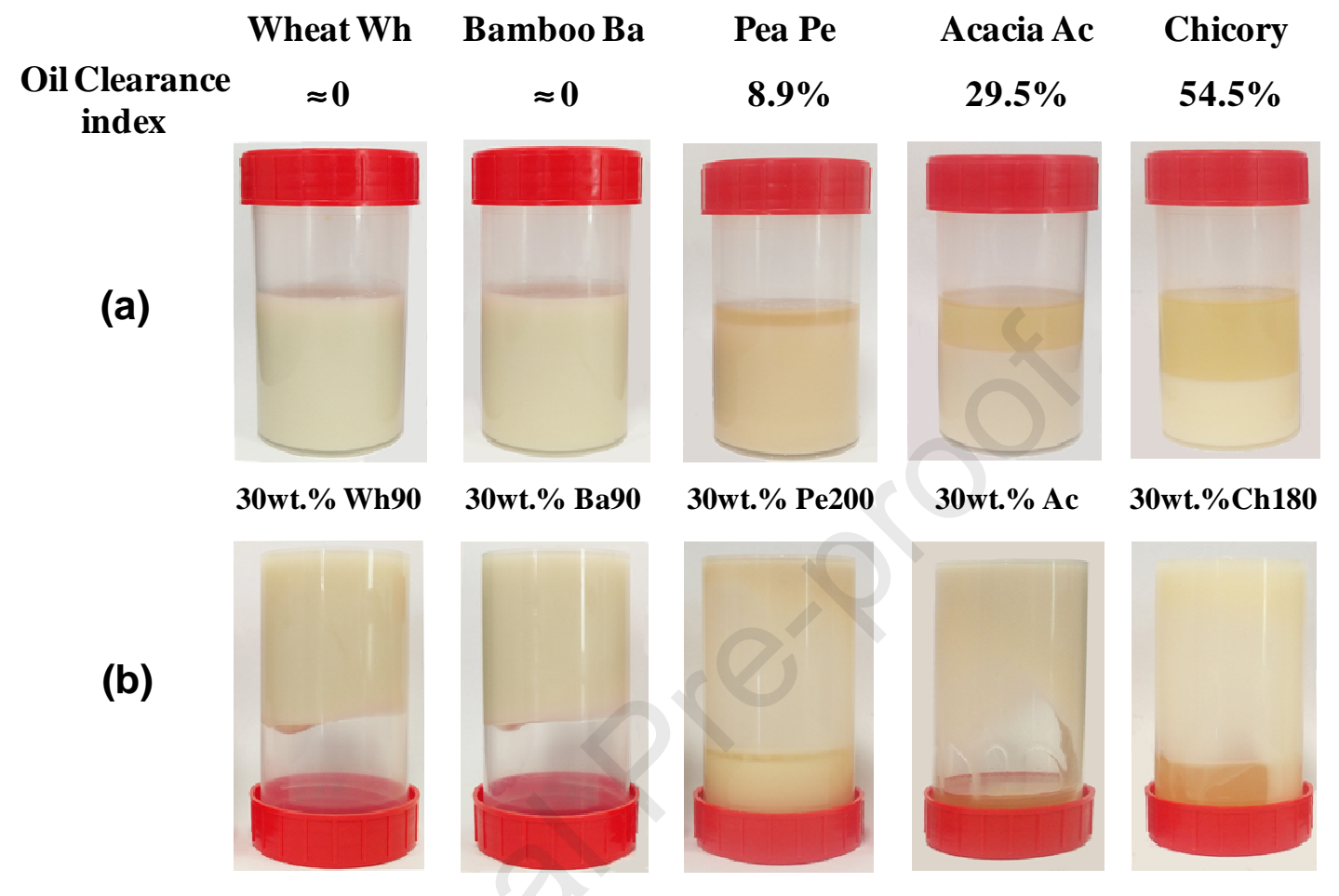


Figure 4

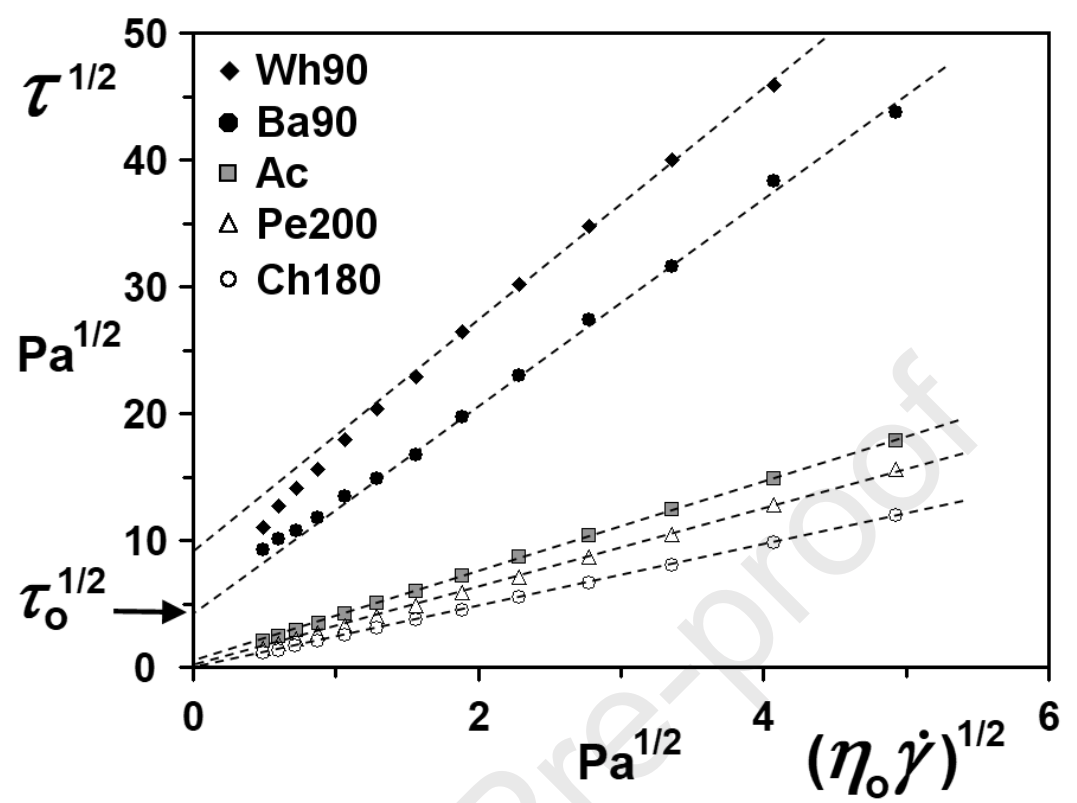


Figure 5

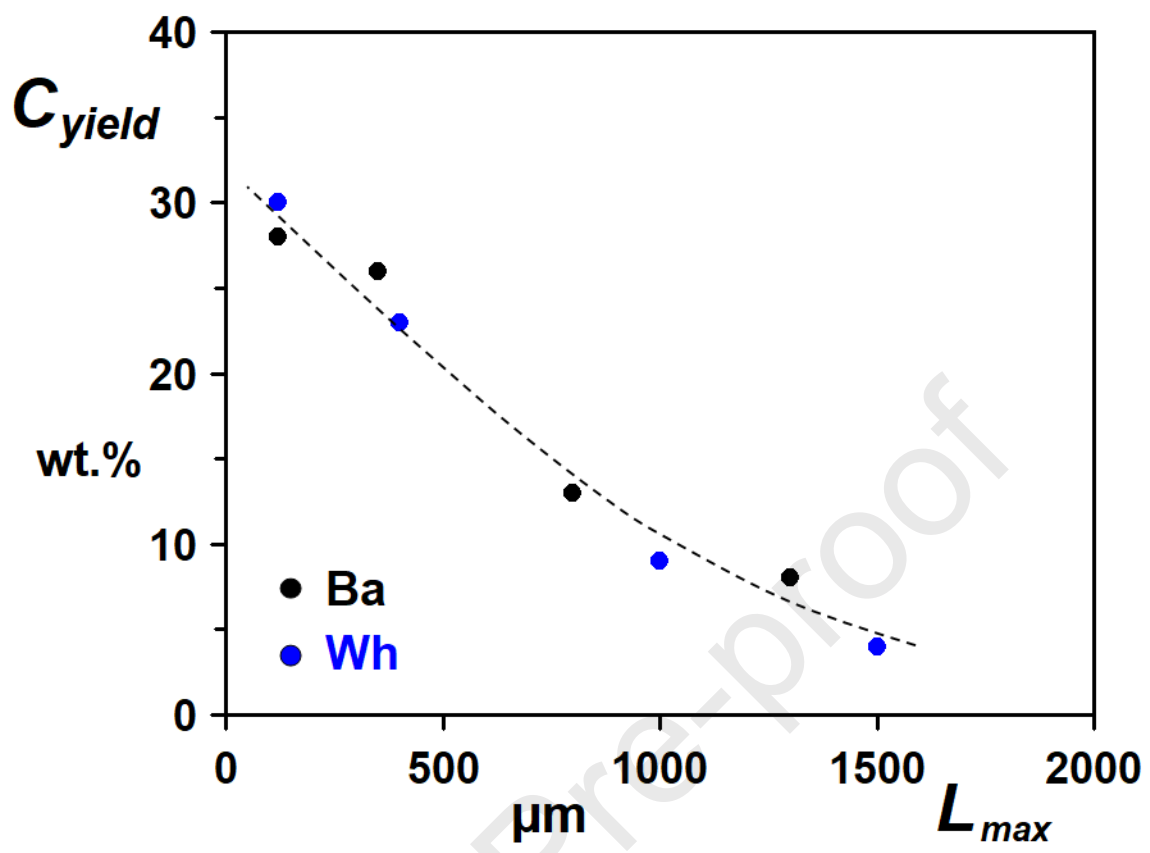


Figure 6
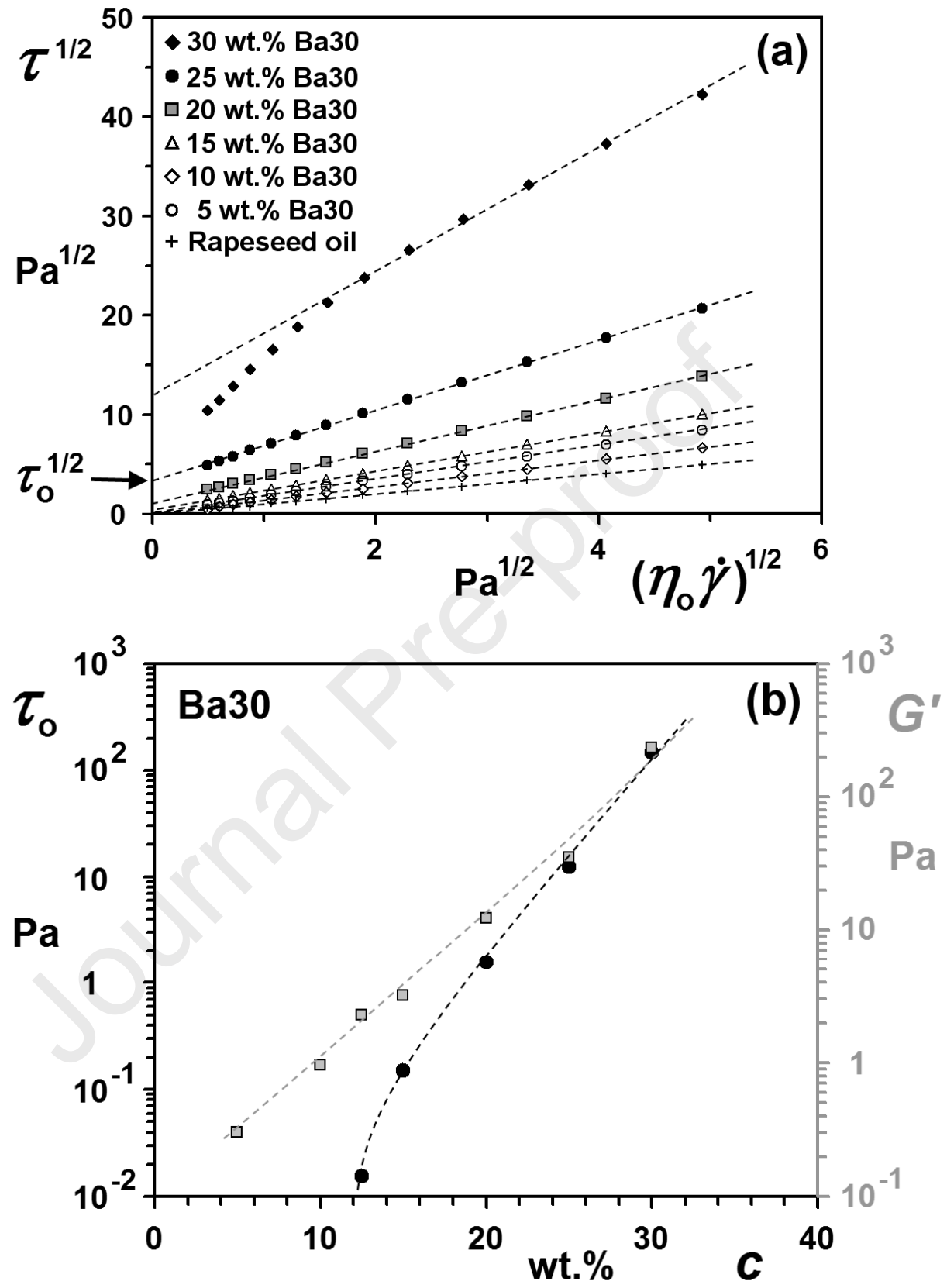
Figure 7

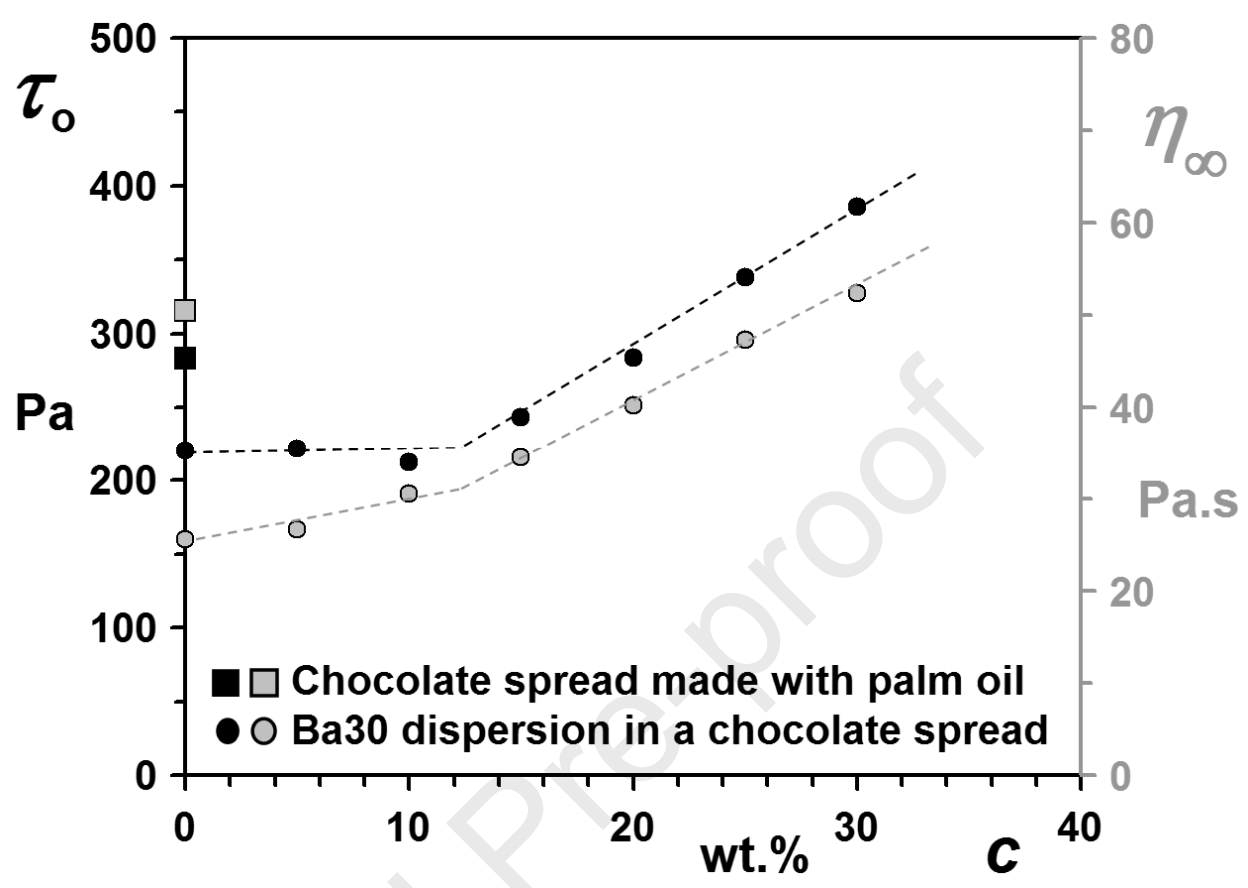


Figure 8

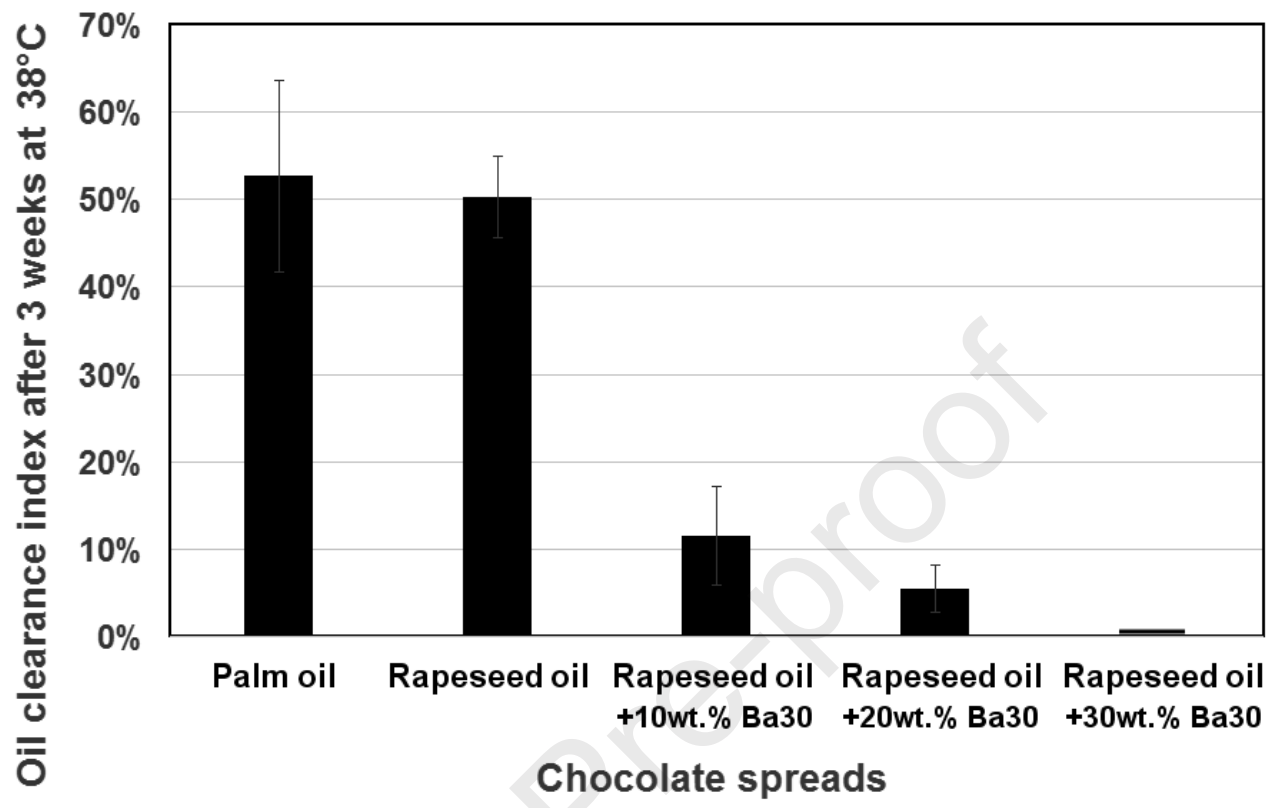


Figure 9
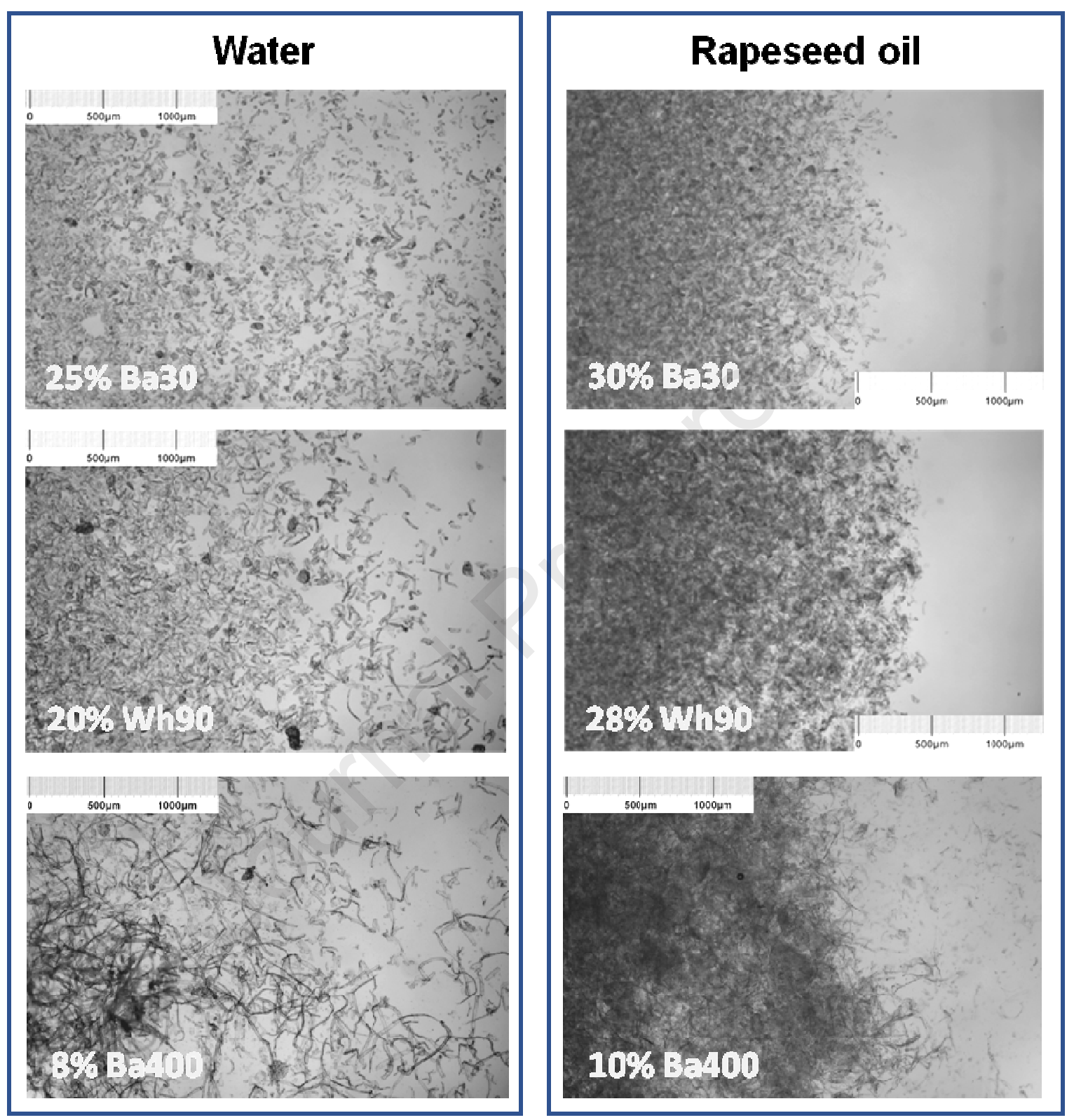


\section{Highlights}

- Oleogelation of an edible oil with cellulose fibers without treatment

- Rapeseed oil texturing requires a minimum cellulose content of $60 \mathrm{wt} . \%$

- Oleogelation results from weak attractive interactions and fiber entanglement

- Use of cellulose fibers for palm oil substitution

- Higher thermal stability of healthier chocolate spreads after palm oil substitution 